\title{
Reoperative aortic root replacement: Outcome in a contemporary series
}

\author{
Jiro Esaki, MD, PhD, ${ }^{a}$ Bradley G. Leshnower, $\mathrm{MD},{ }^{\mathrm{b}}$ Jose N. Binongo, $\mathrm{PhD},{ }^{\mathrm{c}}$ Yi Lasanajak, MPH, \\ LaRonica McPherson, RN, ${ }^{b}$ Vinod H. Thourani, MD, ${ }^{b}$ and Edward P. Chen, MD $^{b}$
}

\begin{abstract}
Objectives: Reoperative aortic root replacement is a challenging procedure associated with significant mortality and morbidity. The purpose of this study was to investigate the outcomes of reoperative aortic root replacement when performed in a number of complex clinical settings and to identify risk factors for operative mortality and long-term survival.

Methods: From 2006 to 2015, 280 consecutive patients at an academic center underwent reoperative aortic root replacement after a variety of previous aortic or cardiac operations. Logistic regression and extended Cox proportional hazards regression analyses were used to determine risk factors for operative mortality and long-term survival, respectively.

Results: The mean age of patients was $52.5 \pm 14.1$ years. Prior operations included proximal aortic replacement in 113 patients, valve surgery in 162 patients, and coronary artery bypass grafting in 46 patients. Concomitant procedures included arch replacement in 135 patients, coronary artery bypass grafting in 68 patients, and mitral valve repair/replacement in 18 patients. Operative mortality was $14.3 \%$. Five-year survival was $74.0 \%$. Univariable analysis did not find previous root replacement, prior proximal aortic surgery, and concomitant arch replacement to be risk factors for operative mortality. In the multivariable analysis, chronic lung disease, prior myocardial infarction, and concomitant mitral valve surgery were risk factors for operative mortality. Age, peripheral artery disease, emergency, and concomitant mitral valve surgery were risk factors for mortality in the late phase.
\end{abstract}

Conclusions: Reoperative aortic root replacement represents complex procedures carrying significant morbidity and mortality. Chronic lung disease, prior myocardial infarction, and concomitant mitral valve surgery were risk factors for operative mortality. Age, peripheral artery disease, emergency, and concomitant mitral valve surgery were risk factors for long-term mortality. (J Thorac Cardiovasc Surg 2017;154:800-8)

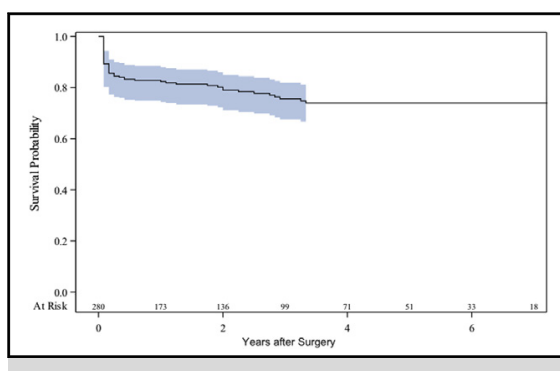

Long-term survival.

\section{Central Message}

Reoperative root replacement after previous cardiac or aortic surgery remains a significant surgical challenge.

\section{Perspective}

Reoperative root replacement is associated with significant morbidity and mortality. Chronic lung disease, prior myocardial infarction, and concomitant mitral valve surgery were risk factors for operative mortality. Age, peripheral artery disease, emergency, and concomitant mitral valve surgery were risk factors for long-term mortality.

See Editorial Commentary page 809.
From the a Department of Cardiovascular Surgery, Otsu Red Cross Hospital, Otsu, Japan; ${ }^{b}$ Division of Cardiothoracic Surgery, Department of Surgery, Emory University School of Medicine; and ${ }^{\mathrm{c}}$ Department of Biostatistics \& Bioinformatics, Rollins School of Public Health, Emory University, Atlanta, Ga.

Read at the 96th Annual Meeting of The American Association for Thoracic Surgery, Baltimore, Maryland, May 14-18, 2016.

Received for publication Nov 23, 2016; revisions received April 1, 2017; accepted for publication April 26, 2017; available ahead of print June 30, 2017.

Address for reprints: Edward P. Chen, MD, Division of Cardiothoracic Surgery, Emory University School of Medicine, 5665 Peachtree Dunwoody Rd, Suite 200, Atlanta, GA 30342 (E-mail: edward.p.chen@emory.edu).

$0022-5223 / \$ 36.00$

Copyright (c) 2017 by The American Association for Thoracic Surgery

http://dx.doi.org/10.1016/j.jtcvs.2017.04.084
Surgical therapy for the treatment of aortic root pathology has undergone significant improvement over the last 20 years. Recent advances in operative technique and

Scanning this QR code will take you to a supplemental video, tables, and figures. To view the AATS 2016 Webcast, see the URL next to the webcast thumbnail.

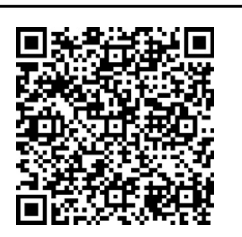



Abbreviations and Acronyms
AVR = aortic valve replacement
$\mathrm{CABG}=$ coronary artery bypass grafting
$\mathrm{CAD}=$ coronary artery disease
$\mathrm{CI}=$ confidence interval
HR = hazard ratio
$\mathrm{OR} \quad=$ odds ratio

improvements in myocardial protection and postoperative management have significantly decreased the surgical risk for aortic root replacement with reports of operative mortality ranging from $1 \%$ to $5 \%$ when performed in the setting of primary cardiac procedures. ${ }^{1-5}$ As the patient population ages, a larger number of patients are requiring redo cardiac operations and reoperations on the aortic root are performed with increasing frequency. ${ }^{6}$

Although there is extensive evidence regarding the safety of the modified Bentall operation when performed as a firsttime procedure, the potential clinical challenges associated with performing this operation in the setting of reoperative surgery are significant. In addition, there is limited information regarding the clinical outcomes of this operation after previous cardiac surgery and in particular after a previous aortic root replacement or other proximal aortic procedures. The purpose of this study was to investigate the outcomes of reoperative root replacement when performed in a number of complex settings and identify risk factors for operative mortality and long-term survival in a contemporary series.

\section{MATERIALS AND METHODS Patients}

This study was conducted with approval of the Institutional Review Board at Emory University in compliance with the Health Insurance Portability and Accountability Act regulations and the Declaration of Helsinki. The Institutional Review Board waived the need for individual patient consent. A review of the Emory Aortic Surgery database identified 867 aortic root replacement procedures that were performed within Emory Healthcare-affiliated hospitals from January 2006 to June 2015. Of those cases, 280 consecutive patients who had undergone an aortic root replacement after previous cardiac or proximal aortic operations were included in this study without exclusion criteria.

To clarify risk factors for operative mortality, the association between relevant preoperative variables and operative mortality was assessed. Also, to know the impact of a specific type of prior intervention on operative and long-term mortality, patients were further divided and 3 more analyses were performed according to their previous surgery. The 3 additional analyses compared patients with a history of aortic root replacement with patients who did not have this history, patients having prior aortic valve replacement (AVR) with patients without prior AVR, and patients with a history of coronary artery bypass grafting (CABG) with those without prior CABG. These analyses are included in Tables E1-E3 and Figures E1-E3 The separate analyses were done because the patient heterogeneity had several different previous operations or a history of multiple different operations. For example, if a patient had a history of aortic root replacement and $\mathrm{CABG}$, the patient was included in both the previous root replacement group and the previous $\mathrm{CABG}$ group.

\section{Operative Technique}

All procedures were performed via redo sternotomy. Methods of arterial and venous cannulation varied according to the perceived risk of cardiac or aortic injury during sternal reentry. Chest computed tomography imaging was vital toward making this determination, and in patients who were thought to have a low risk of cardiac or aortic injury during reentry, central cannulation via the ascending aorta and right atrium was performed after adequate exposure of the heart. Patients who were thought to be at high risk for injury to aorta or heart during sternal reentry had right axillary artery or femoral artery cannulation performed before sternotomy. If the patient had an aortic arch aneurysm, the right axillary artery was usually cannulated and aortic arch reconstruction was performed using hypothermic circulatory arrest with unilateral selective antegrade cerebral perfusion as previously described. ${ }^{7}$ However, retrograde cerebral perfusion or deep hypothermic circulatory arrest alone also was used if the patient had a history of right axillary artery cannulation or if a pseudoaneurysm was positioned in front of the arch and arch vessels prevented easy access.

The specific root procedure performed depended on the patient's characteristics, the aortic valve anatomy, and the surgeon's preference. If the patient was young and the aortic valve cusps did not have significant degeneration, the David V reimplantation method was often used as previously described. ${ }^{8}$ For patients undergoing root replacement using a composite valve conduit, with a mechanical or bioprosthetic valve-conduit, the modified Bentall technique ${ }^{9}$ was performed (Video 1 ). For elderly patients, a bioprosthetic valve-conduit was used. If the patient opted not to take anticoagulation to reduce the risk of bleeding and avoid lifestyle adjustments associated with anticoagulation, a bioprosthesis was used even if the patient was young. For patients with root abscess, root replacement with homograft was performed. For patients who previously underwent mechanical AVR, the valve was inspected, and if valve function was intact, an aortic root graft was sewn to the sewing ring of the previously implanted valve using pledgeted 2-0 braided polyester sutures.

In the majority of cases, the coronary arteries were primarily reimplanted as buttons; however, in patients in whom the coronary ostia were friable because of infection or in patients in whom the coronary arteries could not reach the new graft because of geometry or length issues, a Cabrol extension was used using a vein graft and occasionally a Dacron graft, depending on the surgeon's preference. ${ }^{10}$ The Cabrol technique was defined as an anastomosis between coronary ostia and new graft and was included as one of the techniques in $\mathrm{CABG}$, being categorized as $\mathrm{CABG}$ for non-coronary artery disease (CAD) reason in this study. Cardioplegia

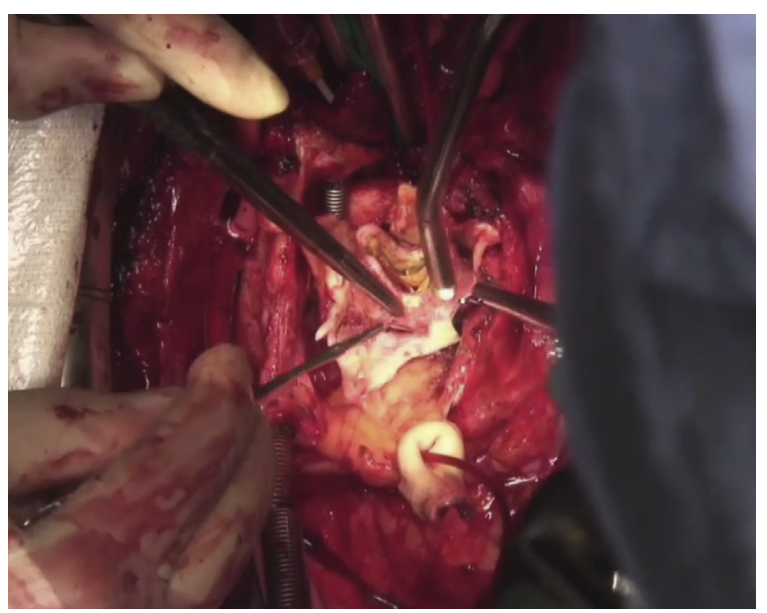

VIDEO 1. Reoperative root replacement after previous AVR. Video available at: http://www.jtcvsonline.org/article/S0022-5223(17)31153-4/addons. 
was typically infused in an antegrade fashion from a root cannula and down any patent vein grafts. If there was a patent internal thoracic artery graft or in the setting of $\mathrm{CAD}$, the internal thoracic artery was not dissected out and continuous retrograde cardioplegia was used.

\section{Long-term Follow-up}

Long-term follow-up was done by chart review and phone contact. Oneyear follow-up was completed in 173 patients $(61.8 \%)$, 2-year follow-up was completed in 136 patients $(48.6 \%), 3$-year follow-up was completed in 99 patients $(35.4 \%)$, 4-year follow-up was completed in 71 patients $(25.4 \%)$, and 5-year follow-up was completed in 51 patients (18.2\%). Median follow-up time was 21 months.

\section{Statistical Analysis}

Preoperative and perioperative variables and postoperative outcomes were summarized using the mean (standard deviation) or median (interquartile range), as appropriate for continuous variables and count (percentage) for categoric variables. Single-predictor logistic regression models were fit to identify risk factors of operative mortality. In building the multivariable logistic regression model, stepwise regression using a $P$ value cutoff of .20 for variable entry and removal was used, starting with all predictors regardless of their significance in the univariable analysis. Then backward elimination was performed, 1 variable at a time, until all predictors in the model were significant at the .05 level. Adjusted odds ratios (ORs) were estimated and reported for risk factors that remained significant at the final stage of the model selection procedure. An extended Cox regression model was subsequently built with a heaviside function; a heaviside function divides time into separate periods (ie, within 30 days and beyond 30 days) and allows unequal hazard ratios (HRs) for each period. This time-segmented analysis permits the selection of separate groups of risk factors for mortality in the early (within 30 days) and late (beyond 30 days) phases. If a variable was significant at either phase, it was used in the multivariable model. Kaplan-Meier curves for survival were plotted to estimate unadjusted survival distributions. When the event of interest was reoperation, death as a competing risk was taken into account, and cumulative incidence functions were constructed to estimate the probability of reoperation on the aortic root or aortic valve. Tests of hypotheses were 2 sided, and a significance level of .05 was used throughout. All data analyses were performed using SAS 9.4 statistical software (SAS Institute Inc, Cary, NC).

\section{RESULTS}

The number and the operative mortality of reoperative root replacements are shown in Figure 1. The operative mortality remained similar during the study period.

Preoperative patient demographics are summarized in Table 1. The mean age was $52.5 \pm 14.1$ years, and the majority were male. The median ejection fraction was $57.8 \%$, and 32 patients $(11.4 \%)$ had prior myocardial infarction. Seventy-two patients $(25.7 \%)$ had bicuspid aortic valve, and 14 patients $(5.0 \%)$ had Marfan syndrome. Six patients $(2.1 \%)$ were treated for type A acute aortic dissection, and 50 patients $(17.9 \%)$ presented with endocarditis or graft infection.

A total of 113 patients $(41.6 \%)$ had previous proximal aortic surgery. Among them, 63 patients $(22.5 \%)$ had undergone previous aortic root replacement. Eighty-five patients $(30.4 \%)$ had prior ascending aortic replacement, and 15 patients $(5.4 \%)$ had prior aortic arch replacement. Forty-seven patients $(16.8 \%)$ had previous repair of acute

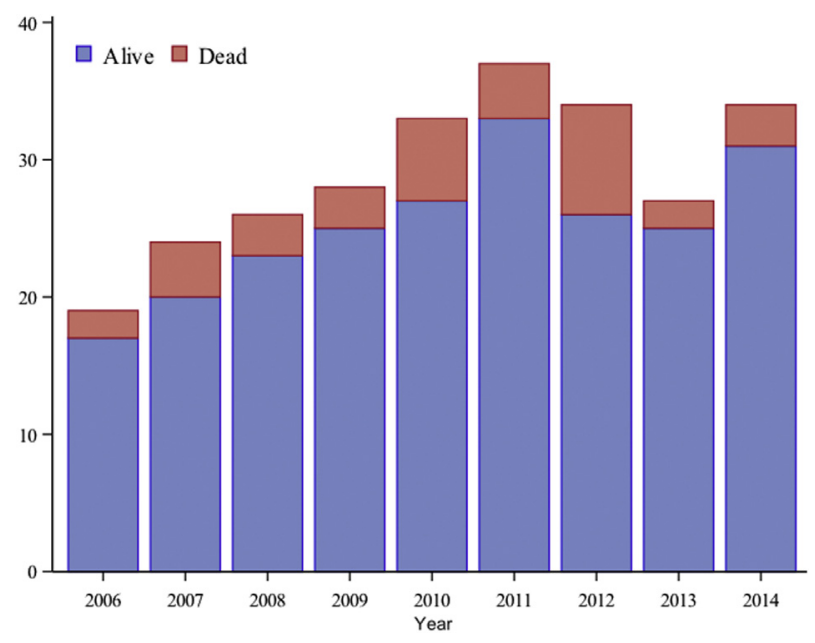

FIGURE 1. The number and operative mortality of reoperative root replacements.

type A aortic dissection. The remainder of the previous procedures in this study population is summarized in Table 1. The median duration from the previous surgeries to the current procedure was 9.3 years.

A total of 178 patients $(63.5 \%)$ underwent surgery for aortic-related pathology, 50 patients $(17.9 \%)$ were treated for endocarditis or graft infection, and 52 patients $(18.6 \%)$ were treated for other valve-related conditions. Among aorta-related indications, aneurysmal disease was present in 159 patients $(56.8 \%$ ), pseudoaneurysm was present in 13 patients $(4.6 \%)$, and acute aortic dissection was present in 6 patients $(2.1 \%)$. Among valve-related indications, structural valve deterioration was indicated in 23 patients $(8.2 \%)$, significant paravalvular leak was noted in 9 patients $(3.2 \%)$, patient-prosthetic mismatch was noted in 8 patients $(2.9 \%)$, thrombus formation on previous implanted mechanical valve was noted in 4 patients $(1.4 \%)$, native aortic insufficiency or stenosis was noted in 6 patients $(2.1 \%)$, and aortic insufficiency after Ross procedure was noted in 1 patient $(0.4 \%)$. One patient required reoperation for a left ventricular outflow tract to right atrial fistula. The patient had a history of AVR with a pericardial patch repair of aortic root abscess for endocarditis and presented with right ventricular volume overload and congestive heart failure due to left ventricular outflow tract to right atrial fistula.

Operative variables are summarized in Table 2. At reoperation, a mechanical valve conduit was used in 62 patients $(22.1 \%)$, a bioprosthetic valve conduit was used in 123 patients $(43.9 \%)$, and a homograft was used in 43 patients $(15.4 \%)$. Twenty-six patients $(9.3 \%)$ underwent valvesparing root replacement, and 5 patients $(1.8 \%)$ underwent the Ross procedure. In 21 patients $(7.5 \%)$, the previously implanted prosthetic valve was preserved. Sixty-eight patients $(24.3 \%)$ underwent $\mathrm{CABG}$, due to $\mathrm{CAD}$ in 28 
TABLE 1. Preoperative characteristics

\begin{tabular}{|c|c|}
\hline Age, y, mean (SD) & $52.5(14.1)$ \\
\hline Male, n $(\%)$ & $216(77.1)$ \\
\hline BMI, mean (SD) & $28.1(6.5)$ \\
\hline Cerebrovascular disease, $\mathrm{n}(\%)$ & $57(20.4)$ \\
\hline Chronic lung disease, $\mathrm{n}(\%)$ & $55(19.6)$ \\
\hline Diabetes mellitus, n (\%) & $46(16.4)$ \\
\hline Dyslipidemia, n (\%) & 167 (59.6) \\
\hline Hypertension, $\mathrm{n}(\%)$ & $222(79.3)$ \\
\hline Peripheral arterial disease, n (\%) & $19(6.8)$ \\
\hline Renal failure, $\mathrm{n}(\%)$ & $11(3.9)$ \\
\hline Dialysis-dependent renal failure, $\mathrm{n}(\%)$ & $5(1.8)$ \\
\hline $\mathrm{CAD}, \mathrm{n}(\%)$ & $68(24.3)$ \\
\hline Previous myocardial infarction, $\mathrm{n}(\%)$ & $32(11.4)$ \\
\hline Ejection fraction $(\%)$, median $(q 1, q 3)$ & $57.8(46.5,60.0)$ \\
\hline $\mathrm{EF}>50 \%, \mathrm{n}(\%)$ & $182(65.0)$ \\
\hline EF $31 \%-50 \%, n(\%)$ & $72(25.7)$ \\
\hline $\mathrm{EF} \leq 30 \%, \mathrm{n}(\%)$ & $26(9.3)$ \\
\hline Bicuspid aortic valve, n (\%) & $72(25.7)$ \\
\hline Marfan syndrome, n (\%) & $14(5.0)$ \\
\hline Acute aortic dissection, $\mathrm{n}(\%)$ & $6(2.1)$ \\
\hline Endocarditis or graft infection, $(\%)$ & $50(17.9)$ \\
\hline Previous aortic surgery, n (\%) & $113(41.6)$ \\
\hline Aortic root replacement, $\mathrm{n}(\%)$ & $63(22.5)$ \\
\hline Ascending aorta replacement, n (\%) & $85(30.4)$ \\
\hline Aortic arch replacement, $\mathrm{n}(\%)$ & $15(5.4)$ \\
\hline $\begin{array}{l}\text { Type A dissection repair including root, ascending } \\
\text { and arch replacement, } \mathrm{n}(\%)\end{array}$ & $47(16.8)$ \\
\hline $\begin{array}{l}\text { Previous valve surgery, excluding root replacement, } \\
\qquad \mathrm{n}(\%)\end{array}$ & $162(57.9)$ \\
\hline AVR, n $(\%)$ & $128(45.7)$ \\
\hline Mitral valve replacement/repair, n (\%) & $26(9.3)$ \\
\hline Pulmonic valve replacement/repair, n (\%) & $22(7.9)$ \\
\hline Previous CABG, $\mathrm{n}(\%)$ & $46(16.4)$ \\
\hline Years from previous surgery, median (q1, q3) & $9.3(3.7,15.4)$ \\
\hline
\end{tabular}

patients (10.0\%); adhesion, anatomy, infection, or injury in 33 patients $(11.8 \%)$; and new myocardial ischemia from coronary malperfusion after button reimplantation in 7 patients $(2.5 \%)$. Among them, Cabrol extension was used in 15 patients $(5.4 \%)$. A total of 106 patients $(37.9 \%)$ underwent hemiarch replacement, and 29 patients $(10.4 \%)$ underwent total arch replacement.

Thirteen patients were placed on cardiopulmonary bypass before re-sternotomy because of a high risk of cardiac or aortic injury during reentry. Among them, 9 patients underwent axillary artery cannulation and 4 patients underwent femoral artery cannulation. Seven patients were placed on cardiopulmonary bypass during reentry because of cardiac or aortic injury. Among them, 6 patients underwent axillary artery cannulation, and 1 patient underwent femoral artery cannulation.

Operative mortality and morbidity are summarized in Table 3. Fourteen patients $(5.0 \%)$ required new dialysis,
TABLE 2. Operation data

\begin{tabular}{lc}
\hline Emergency, $\mathrm{n}(\%)$ & $13(4.6)$ \\
Root replacement & \\
With mechanical valve, $\mathrm{n}(\%)$ & $62(22.1)$ \\
With bioprosthetic valve, $\mathrm{n}(\%)$ & $123(43.9)$ \\
With homograft, $\mathrm{n}(\%)$ & $43(15.4)$ \\
With valve sparing, $\mathrm{n}(\%)$ & $26(9.3)$ \\
With Ross procedure, $\mathrm{n}(\%)$ & $5(1.8)$ \\
With prosthesis sparing, $\mathrm{n}(\%)$ & $21(7.5)$ \\
Mitral valve replacement or repair, $\mathrm{n}(\%)$ & $18(6.4)$ \\
Pulmonic valve replacement, $\mathrm{n}(\%)$ & $25(8.9)$ \\
Tricuspid valve repair, $\mathrm{n}(\%)$ & $5(1.8)$ \\
CABG, $\mathrm{n}(\%)$ & $68(24.3)$ \\
Due to CAD, $\mathrm{n}(\%)$ & $28(10.0)$ \\
Due to adhesion, $\mathrm{n}(\%)$ & $7(2.5)$ \\
Due to anatomy, $\mathrm{n}(\%)$ & $13(4.6)$ \\
Due to infection, $\mathrm{n}(\%)$ & $4(1.4)$ \\
Due to injury, $\mathrm{n}(\%)$ & $9(3.2)$ \\
Due to new myocardial ischemia, $\mathrm{n}(\%)$ & $7(2.5)$ \\
Cabrol extension, $\mathrm{n}(\%)$ & $15(5.4)$ \\
Aortic arch replacement, $\mathrm{n}(\%)$ & $135(48.2)$ \\
Hemiarch replacement, $\mathrm{n}(\%)$ & $106(37.9)$ \\
Total arch replacement, $\mathrm{n}(\%)$ & $29(10.4)$ \\
Arterial cannulation site, $\mathrm{n}(\%)$ & \\
Aorta, $\mathrm{n}$ (\%) & $106(37.9)$ \\
Axillary artery, $\mathrm{n}(\%)$ & $158(56.4)$ \\
Femoral artery, $\mathrm{n}(\%)$ & $16(5.7)$ \\
CPB time (min), median (q1, q3) & $240.5(205.5,283.0)$ \\
Crossclamp time (min), median (q1, $\mathrm{q} 3)$ & $198.0(171.5,225.0)$ \\
Circulatory arrest, $\mathrm{n}(\%)$ & $144(51.4)$ \\
Antegrade cerebral perfusion, $\mathrm{n}(\%)$ & $124(44.3)$ \\
Antegrade and retrograde cerebral perfusion, $\mathrm{n}$ & $2(0.7)$ \\
$\quad(\%)$ & \\
Retrograde cerebral perfusion, $\mathrm{n}(\%)$ & $(2.9)$ \\
Deep hypothermic circulatory arrest, $\mathrm{n}(\%)$ & $(22.0,38.5)$ \\
Circulatory arrest time (min), median (q1, q3) & \\
\hline
\end{tabular}

$C A B G$, Coronary artery bypass grafting; $C A D$, coronary artery disease; $C P B$, cardiopulmonary bypass.

12 patients $(4.3 \%)$ had transient neurologic dysfunction, and 14 patients $(5.0 \%)$ had permanent neurologic dysfunction. The median intensive care unit stay was 67.5 hours, and the median length of stay was 7.0 days. Operative mortality was 40 patients $(14.3 \%)$. The causes of operative mortality were heart failure in 13 patients, bleeding in 10 patients, multisystem failure in 9 patients, stroke in 5 patients, respiratory failure in 2 patients, and ischemic bowel in 1 patient.

Five-year survival of all patients was $74.0 \%$ (95\% confidence interval [CI], 67.4-79.4) (Figure 2). The number of late deaths was 21 . The causes of late death were endocarditis or graft infection in 3 patients, heart failure in 1 patient, operative mortality after thoracoabdominal aneurysm repair in 2 patients, operative mortality after pseudoaneurysm repair of aortic root in 1 patient, stroke in 3 patients, sepsis in 1 patient, and unknown in 10 patients. 
TABLE 3. Mortality and morbidities

\begin{tabular}{lc}
\hline Reexploration for bleeding, $\mathrm{n}(\%)$ & $31(11.1)$ \\
Prolonged ventilation $(>24 \mathrm{~h}), \mathrm{n}(\%)$ & $105(37.5)$ \\
Intra-aortic balloon pump required, $\mathrm{n}(\%)$ & $60(21.4)$ \\
$\quad$ Preoperative (prophylactic) & $12(4.3)$ \\
$\quad$ Intraoperative & $43(15.4)$ \\
$\quad$ Postoperative & $5(1.8)$ \\
New dialysis required, n (\%) & $14(5.0)$ \\
Transient neurologic dysfunction, n (\%) & $12(4.3)$ \\
Permanent neurologic dysfunction, $\mathrm{n}(\%)$ & $14(5.0)$ \\
Pacemaker implantation, $\mathrm{n}(\%)$ & $9(3.2)$ \\
Deep sternal infection, $\mathrm{n}(\%)$ & $3(1.1)$ \\
ICU stay (h), median (q1, q3) & $67.5(40.5,134.3)$ \\
Length of stay (d), median (q1, q3) & $7.0(5.0,11.0)$ \\
Operative mortality, $\mathrm{n}(\%)$ & $40(14.3)$ \\
\hline
\end{tabular}

$I C U$, Intensive care unit.

Five-year cumulative incidence of reoperation on the aortic root or aortic valve was $4.6 \%$ (95\% CI, 2.3-9.3). The causes of reoperation were aortic insufficiency in 4 patients, infection in 3 patients, and pseudoaneurysm in 1 patient.

Chronic lung disease (OR, 3.61; 95\% CI, 1.65-7.93), prior myocardial infarction (OR, 3.76; 95\% CI, 1.579.02), and concomitant mitral valve surgery (OR, 7.04; $95 \%$ CI, 2.37-20.92) were identified as risk factors for operative mortality in multivariable logistic regression analysis (Table 4). However, previous aortic root replacement, previous proximal aortic surgery, prior type A aortic dissection repair, concomitant aortic arch replacement, retrograde cerebral perfusion, deep hypothermic circulatory arrest, renal failure, and endocarditis were not found to be risk factors for operative death.

Age (HR, 2.02; 95\% CI, 1.36-3.00), prior myocardial infarction (HR, 4.47; 95\% CI, 1.89-10.54), emergency (HR, 5.23; 95\% CI, 1.93-14.18), and CABG for nonCAD reason (HR, 4.32; 95\% CI, 1.92-9.71) were identified as risk factors for early-phase mortality in the extended Cox regression analysis (Table 5). Age (HR, 1.84; 95\% CI, 1.222.77), peripheral arterial disease (HR, 5.43; 95\% CI, 2.0014.77), emergency status (HR, 6.07; 95\% CI, 1.74-21.12),

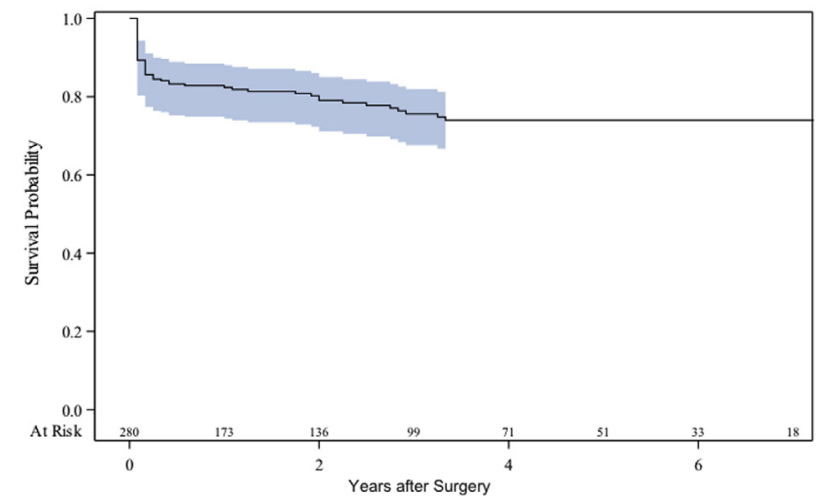

FIGURE 2. Long-term survival. and mitral valve surgery (HR, 4.50; 95\% CI, 1.51-13.45) were identified as risk factors for late-phase mortality in the extended Cox regression analysis (Table 5).

Operative mortality in patients with previous root replacement was $9.5 \%$, which was not significantly different from that of the patients without previous root replacement (Table E3). Operative mortality in patients with previous AVR was $14.1 \%$, which also was not significantly different from that of the patients without previous AVR (Table E3). However, operative mortality in patients with previous $C A B G$ was $26.1 \%$, which was significantly higher than that of the patients without previous CABG $(P=.01)$ (Table E3). Five-year survival in patients with and without previous root replacement was not different $(80.5 \%, 72.1 \%, \log$-rank $P=.21)$ (Figure E1). Five-year survival in patients with and without previous AVR was not different $(71.8 \%, 75.8 \%$, log-rank $P=.54)$ (Figure E2). However, 5-year survival in patients with previous $\mathrm{CABG}$ was significantly lower than that of patients without previous CABG $(55.1 \%, 77.8 \%, \quad$ log-rank $P=.0064$ ) (Figure E3).

\section{DISCUSSION}

To date, only a limited number of studies have been performed examining the outcomes of redo aortic root replacement. Therefore, in this study we sought to evaluate and examine the operative outcomes and survival of patients undergoing redo aortic root replacement in a contemporary series after a variety of previous cardiac and aortic operations. It is believed that the number of patients in this study represents one of the larger series of aortic root replacement procedures being reported in the setting of reoperative cardiac and aortic surgery. The overall operative mortality in this series was $14.3 \%$, which was higher than those of prior reports, ranging from $2 \%$ to $18 \%$. ${ }^{6,11-16}$ However, a significant number of concomitant procedures were performed in this study compared with other series, including aortic arch reconstruction $(48.2 \%)$, CABG $(24.3 \%)$, and multivalve interventions, which can partially explain this finding. In addition, patients were not excluded on the basis of the type of prior procedure or clinical scenario ${ }^{14}$ and most likely encompassed a wider range of operative risk than other series. Last, operative results also could have been affected by the preoperative demographics. The prevalence of preoperative comorbid conditions was higher in this study than in other reports, as $20.4 \%$ had cerebrovascular disease, $16.4 \%$ had diabetes mellitus, $6.8 \%$ had peripheral artery disease, and $24.3 \%$ had CAD. In addition, the prevalence of low ejection fraction of less than $30 \%$ was higher in the present study at $9.3 \%$ of patients. In a smaller, similar study of 56 patients by Kirsch and colleagues, ${ }^{6}$ operative mortality was worse than the current study and was found to be $17.9 \%$. 
TABLE 4. Risk factors for operative mortality

\begin{tabular}{|c|c|c|c|c|}
\hline & \multicolumn{2}{|c|}{ Univariable analysis } & \multicolumn{2}{|c|}{ Multivariable analysis } \\
\hline & OR $(95 \%$ CI $)$ & $P$ value & OR $(95 \%$ CI $)$ & $P$ value \\
\hline Age & $1.05(1.02-1.08)$ & $<.001$ & & \\
\hline Male & $0.65(0.31-1.36)$ & .25 & & \\
\hline Cerebrovascular disease & $1.16(0.52-2.60)$ & .72 & & \\
\hline Chronic lung disease & $3.00(1.45-6.19)$ & .003 & $3.61(1.65-7.93)$ & .001 \\
\hline Diabetes & $1.59(0.70-3.62)$ & .27 & & \\
\hline Peripheral arterial disease & $5.21(1.95-13.91)$ & .001 & & \\
\hline Renal failure & $2.35(0.60-9.27)$ & .22 & & \\
\hline Dialysis-dependent renal failure & $1.51(0.17-13.90)$ & .71 & & \\
\hline CAD & $2.74(1.36-5.51)$ & .005 & & \\
\hline Prior myocardial infarction & $3.96(1.73-9.04)$ & .001 & $3.76(1.57-9.02)$ & .003 \\
\hline Ejection fraction & $0.98(0.96-1.00)$ & .10 & & \\
\hline Bicuspid aortic valve & $0.20(0.06-0.67)$ & .009 & & \\
\hline Marfan syndrome & $0.45(0.06-3.52)$ & .45 & & \\
\hline Acute type A dissection & $1.21(0.14-10.59)$ & .87 & & \\
\hline Endocarditis/graft Infection & $1.96(0.90-4.24)$ & .09 & & \\
\hline Previous CABG & $2.60(1.21-5.59)$ & .01 & & \\
\hline Previous AVR & $0.97(0.49-1.90)$ & .92 & & \\
\hline Previous proximal aortic surgery except for root replacement & $1.18(0.51-2.74)$ & .70 & & \\
\hline Previous aortic root replacement & $0.57(0.23-1.42)$ & .22 & & \\
\hline Previous type A dissection repair & $1.83(0.82-4.06)$ & .14 & & \\
\hline Emergency & $5.87(1.86-18.52)$ & .003 & & \\
\hline CABG for CAD & $2.75(1.12-6.76)$ & .03 & & \\
\hline $\mathrm{CABG}$ for non-CAD reason & $2.76(1.25,6.11)$ & .01 & & \\
\hline Mitral valve repair/replacement & $4.42(1.60-12.19)$ & .004 & $7.04(2.37-20.92)$ & $<.001$ \\
\hline Pulmonic valve replacement & $0.50(0.11-2.19)$ & .36 & & \\
\hline Aortic arch replacement & $0.68(0.34-1.34)$ & .26 & & \\
\hline Circulatory arrest time & $1.02(0.99-1.04)$ & .19 & & \\
\hline Retrograde cerebral perfusion & - & .98 & & \\
\hline Deep hypothermic circulatory arrest & $3.81(0.87-16.62)$ & .08 & & \\
\hline
\end{tabular}

Statistically significant results are shown in boldface. $O R$, Odds ratio; $C I$, confidence interval; $C A D$, coronary artery disease; $C A B G$, coronary artery bypass grafting; $A V R$, aortic valve replacement.

Jassar and colleagues ${ }^{14}$ reported that age, diabetes, CABG, and endocarditis were risk factors for in-hospital mortality using multivariable analysis. Other studies have found age and CABG to be associated with operative death. ${ }^{6,13,16}$ In this study, chronic lung disease, prior myocardial infarction, and concomitant mitral valve surgery were found to be risk factors for operative mortality. Contrary to previous reports, endocarditis was not a risk factor in the multivariable analysis of this study. A possible reason is that this study did not have sufficient events and power to detect a difference.

Jassar and colleagues ${ }^{14}$ reported that age, renal failure, diabetes, heart failure, $\mathrm{CABG}$, and endocarditis were risk factors for late mortality and bicuspid valve and male gender were protective factors for late mortality. Garrido-Olivares and colleagues ${ }^{16}$ reported that age and endocarditis were risk factors for late mortality. In this study, time-segmented analysis indicates that age, prior myocardial infarction, emergency, and CABG for nonCAD reason are risk factors for mortality in the early phase, and age, peripheral artery disease, emergency, and concomitant mitral valve surgery are risk factors for mortality in the late phase. Renal failure appeared to be associated with worse outcome, but, surprisingly, was not a significant predictor. It was also interesting that endocarditis was significant risk factor in univariable analysis, but was not found to be a risk factor in multivariable analysis. A possible reason for both these observations is that this study did not have sufficient numbers and power to detect a difference.

It is noted that not only prior myocardial infarction but also $\mathrm{CABG}$ for non-CAD reasons was one of the risk factors for mortality in the early hazard phases. In this study, 14.2\% of patients required CABG for non-CAD reasons. Harvesting vein grafts as part of the overall surgical strategy was performed if there were concerns regarding infection involving coronary artery ostia, geometry, and inadequate distance issues between coronary buttons and valveconduit due to adhesions or size mismatch of the native aortic root and new prosthetic graft.

In this study, previous root replacement is not associated with higher operative mortality. Operative mortality of the 
TABLE 5. Time-segmented risk factor analysis for mortality

\begin{tabular}{|c|c|c|c|c|c|c|c|c|}
\hline & \multicolumn{4}{|c|}{ Univariable analysis } & \multicolumn{4}{|c|}{ Multivariable analysis } \\
\hline & \multicolumn{2}{|c|}{ Early phase (30 d) } & \multicolumn{2}{|c|}{ Late phase (beyond $30 \mathrm{~d}$ ) } & \multicolumn{2}{|c|}{ Early phase (30 d) } & \multicolumn{2}{|c|}{ Late phase (beyond $30 \mathrm{~d}$ ) } \\
\hline & HR $(95 \%$ CI $)$ & $P$ value & HR $(95 \%$ CI $)$ & $P$ value & HR $(95 \%$ CI $)$ & $P$ value & HR $(95 \%$ CI $)$ & $P$ value \\
\hline Age & $2.09(1.38-3.17)$ & .001 & $1.63(1.10-2.41)$ & .02 & $2.02(1.36-3.00)$ & .001 & $1.84(1.22-2.77)$ & .004 \\
\hline Male & $0.81(0.36-1.81)$ & .60 & $0.91(0.39-2.11)$ & .82 & & & & \\
\hline Cerebrovascular disease & $1.45(0.65-3.27)$ & .36 & $0.42(0.13-1.38)$ & .15 & & & & \\
\hline Chronic lung disease & $3.41(1.66-7.03)$ & .001 & $1.49(0.64-3.46)$ & .35 & & & & \\
\hline Diabetes & $1.59(0.68-3.71)$ & .28 & $1.37(0.56-3.34)$ & .49 & & & & \\
\hline Peripheral arterial disease & $3.89(1.59-9.51)$ & .003 & $3.73(1.43-9.71)$ & .007 & $2.32(0.88-6.12)$ & .09 & $5.43(2.00-14.77)$ & .001 \\
\hline Renal failure & $2.99(0.91-9.84)$ & .07 & $3.23(0.98-10.62)$ & .05 & & & & \\
\hline Dialysis-dependent renal failure & $2.00(0.27-14.64)$ & .50 & $3.82(0.91-16.01)$ & .07 & & & & \\
\hline CAD & $2.92(1.43-5.99)$ & .003 & $1.68(0.79-3.56)$ & .18 & & & & \\
\hline Prior myocardial infarction & $4.41(2.06-9.42)$ & $<.001$ & $0.69(0.17-2.91)$ & .62 & $4.47(1.89-10.54)$ & .001 & $0.61(0.14-2.59)$ & .50 \\
\hline Ejection fraction & $0.74(0.54-1.00)$ & .05 & $0.82(0.60-1.12)$ & .21 & & & & \\
\hline Bicuspid aortic valve & $0.20(0.05-0.82)$ & .03 & $0.36(0.13-1.02)$ & .05 & & & & \\
\hline Marfan syndrome & $0.64(0.09-4.72)$ & .66 & $1.43(0.34-6.00)$ & .63 & & & & \\
\hline Acute type A dissection & $1.63(0.22-11.94)$ & .63 & $3.99(0.95-16.81)$ & .06 & & & & \\
\hline Endocarditis/graft infection & $2.44(1.14-5.22)$ & .02 & $1.42(0.58-3.46)$ & .44 & & & & \\
\hline Previous CABG & $2.31(1.06-5.04)$ & .04 & $2.02(0.90-4.51)$ & .09 & & & & \\
\hline Previous AVR & $0.90(0.44-1.86)$ & .78 & $1.48(0.73-3.00)$ & .28 & & & & \\
\hline $\begin{array}{l}\text { Previous proximal aortic surgery } \\
\text { except for root replacement }\end{array}$ & $1.16(0.47-2.84)$ & .75 & $0.68(0.24-1.94)$ & .47 & & & & \\
\hline Previous aortic root replacement & $0.68(0.26-1.77)$ & .42 & $0.63(0.24-1.64)$ & .34 & & & & \\
\hline Previous type A dissection repair & $1.88(0.84-4.22)$ & .13 & $0.99(0.38-2.58)$ & .98 & & & & \\
\hline Emergency & $4.84(1.85-12.66)$ & .001 & $4.07(1.23-14.46)$ & .02 & $5.23(1.93-14.18)$ & .001 & $6.07(1.74-21.12)$ & .005 \\
\hline $\mathrm{CABG}$ for $\mathrm{CAD}$ & $2.99(1.28-6.96)$ & .01 & $2.05(0.79-5.34)$ & .14 & & & & \\
\hline $\mathrm{CABG}$ for non-CAD & $3.28(1.54-7.02)$ & .002 & $1.33(0.46-3.80)$ & .60 & $4.32(1.92-9.71)$ & $<.001$ & $1.86(0.63-5.51)$ & .26 \\
\hline Mitral valve repair/replacement & $1.67(0.51-5.51)$ & .40 & $2.92(1.02-8.36)$ & .046 & $1.89(0.52-6.89)$ & .33 & $4.50(1.51-13.45)$ & .007 \\
\hline Pulmonic valve replacement & $0.34(0.05-2.49)$ & .29 & $0.90(0.27-2.94)$ & .85 & & & & \\
\hline Aortic arch replacement & $0.70(0.34-1.46)$ & .34 & $1.05(0.52-2.12)$ & .89 & & & & \\
\hline Circulatory arrest time & $1.40(0.96-2.03)$ & .08 & $1.03(0.65-1.63)$ & .90 & & & & \\
\hline Retrograde cerebral perfusion & - & - & $1.00(0.14-7.31)$ & .99 & & & & \\
\hline Deep hypothermic circulatory arrest & $4.41(1.34-14.55)$ & .01 & $1.53(0.21-11.23)$ & .68 & & & & \\
\hline
\end{tabular}

Statistically significant results are shown in boldface. $H R$, Hazard ratio; $C I$, confidence interval; $C A D$, coronary artery disease; $C A B G$, coronary artery bypass grafting; $A V R$, aortic valve replacement.

true redo root replacement in this study was $9.5 \%$, which was higher than in previous reports, ranging from $2.4 \%$ to $6 \% .{ }^{14-16}$ However, patients with previous root replacement in our study required more concomitant $\mathrm{CABG}$ and aortic arch replacement than the prior studies ${ }^{14,16}$ and were older than those in the previous reports. ${ }^{15}$

In this study, the operative mortality of root replacement after previous CABG reached $26.1 \%$, which was higher than that of the entire population. There are several possible reasons for this observation. One explanation lies in the patient characteristics. In patients with previous CABG, the mean age of patients was greater and there was a higher incidence of peripheral artery disease, prior myocardial infarction, $\mathrm{CAD}$, and chronic lung disease. Prior myocardial infarction and chronic lung disease were particularly significant risk factors for operative mortality in multivariable analysis, which may explain higher operative mortality. A second reason lies in the potentially greater degree of difficulty in providing adequate myocardial protection in the setting of CAD at the time of operative intervention, particularly in the setting of a patent internal thoracic artery graft. Other possible reasons include the need for concomitant $\mathrm{CABG}$ and the technical complexity required for not only dissecting out an aortic root in the setting of previous grafts but also reattaching these grafts again, which sometimes required Cabrol extension or additional bypass procedures. However, CABG due to injury was $2.2 \%$ in the previous CABG group, which was not significantly different from the whole group; therefore, this was not the reason for the higher mortality in the previous CABG group.

Despite the increased operative mortality of the current study, the overall 5-year survival in this study was $74.0 \%$. Other series have reported 5-year survival ranging from $65.7 \%$ to $89 \% .^{6,12,14,15}$ It seems that survival was influenced by patient age and operative mortality, and the survival of patients who survived the operation is similar between studies. 
Long-term survival of patients who had a history of CABG was poorer than that of the entire population. The reason was thought to be higher operative mortality, rather than late death, considering previous CABG was a significant factor in the early phase and not a significant factor in the late phase in univariable analysis.

A bioprosthesis was used even if the patient was young and opted not to take anticoagulation to reduce the risk of bleeding and avoid lifestyle adjustments associated with anticoagulation. This resulted in tissue conduits being used in the $43.9 \%$ of all patients even though the average age was 52.5 years. One of the next reoperation options could be a valve-in-valve TAVR for such cases when structural valve dysfunction occurs and the patient is deemed too high risk for the third reoperative intervention.

\section{Study Limitations}

This is a retrospective study and may be prone to selection bias, and results may be affected by surgeons' preferences. Our 2 surgeons specialize in aortic surgery, which might not make the result generalizable. Follow-up duration was short and not complete. This study encompassed a variety of clinical settings and previous cardiac or aortic surgeries, and the results may not be generalizable to specific situations.

\section{CONCLUSIONS}

Reoperative root replacement after previous cardiac and aortic surgery remains a significant surgical challenge. Chronic lung disease, prior myocardial infarction, and concomitant mitral valve surgery were risk factors for operative mortality. Age, peripheral artery disease, emergency, and concomitant mitral valve surgery were risk factors for long-term mortality.

\section{Webcast}

You can watch a Webcast of this AATS meeting presentation by going to: http://webcast.aats.org/2016/Video/ Tuesday/05-17-16_Ballroom_I_1655_Esaki-800.mp4.

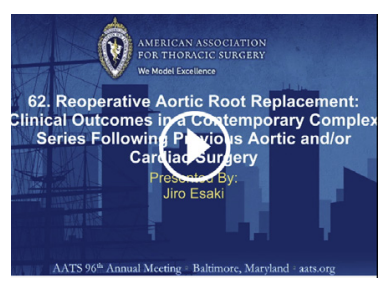

\section{Conflict of Interest Statement}

B.G.L. is a consultant for CryoLife. V.H.T. is on the advisory board for Edwards Lifesciences and St Jude Medical and has received research grants from Edwards Lifesciences, Medtronic, St Jude Medical, and Boston Scientific.
All other authors have nothing to disclose with regard to commercial support.

\section{References}

1. Stamou SC, Williams ML, Gunn TM, Hagberg RC, Lobdell KW, Kouchoukos NT. Aortic root surgery in the United States: a report from the Society of Thoracic Surgeons database. J Thorac Cardiovasc Surg. 2015;149: 116-22.e114.

2. Etz CD, Bischoff MS, Bodian C, Roder F, Brenner R, Griepp RB, et al. The Bentall procedure: is it the gold standard? A series of 597 consecutive cases. J Thorac Cardiovasc Surg. 2010;140:S64-70; discussion S86-91.

3. Etz CD, Bischoff MS, Bodian C, Roder F, Brenner R, Griepp RB, et al. Surgery for aneurysms of the aortic root: a 30-year experience. Circulation. 2004;110:1364-71.

4. Urbanski PP, Heinz N, Zhan X, Hijazi H, Zacher M, Diegeler A. Modified bioBentall procedure: 10-year experience. Eur J Cardiothorac Surg. 2010;37:1317-21.

5. Gott VL, Greene PS, Alejo DE, Cameron DE, Naftel DC, Miller DC, et al. Replacement of the aortic root in patients with Marfan's syndrome. $N$ Engl J Med. 1999;340:1307-13.

6. Kirsch EW, Radu NC, Mekontso-Dessap A, Hillion ML, Loisance D. Aortic root replacement after previous surgical intervention on the aortic valve, aortic root, or ascending aorta. J Thorac Cardiovasc Surg. 2006;131:601-8.

7. Halkos ME, Kerendi F, Myung R, Kilgo P, Puskas JD, Chen EP. Selective antegrade cerebral perfusion via right axillary artery cannulation reduces morbidity and mortality after proximal aortic surgery. J Thorac Cardiovasc Surg. 2009; 138:1081-9

8. Leshnower BG, Guyton RA, Myung RJ, Puskas JD, Kilgo PD, McPherson L, et al. Expanding the indications for the David V aortic root replacement: early results. J Thorac Cardiovasc Surg. 2012;143:879-84.

9. Kouchoukos NT, Wareing TH, Murphy SF, Perrillo JB. Sixteen-year experience with aortic root replacement. Results of 172 operations. Ann Surg. 1991;214:308-20.

10. Kourliouros A, Soni M, Rasoli S, Grapsa J, Nihoyannopoulos P, O'Regan D, et al Evolution and current applications of the Cabrol procedure and its modifications. Ann Thorac Surg. 2011;91:1636-41.

11. Etz CD, Plestis KA, Homann TM, Bodian CA, Di Luozzo G, Spielvogel D, et al Reoperative aortic root and transverse arch procedures: a comparison with contemporaneous primary operations. J Thorac Cardiovasc Surg. 2008;136: 860-7. 867.e1-3.

12. Malvindi PG, van Putte BP, Heijmen RH, Schepens MA, Morshuis WJ. Reoperations on the aortic root: experience in 46 patients. Ann Thorac Surg. 2010;89:81-6.

13. Szeto WY, Bavaria JE, Bowen FW, Geirsson A, Cornelius K, Hargrove WC, et al Reoperative aortic root replacement in patients with previous aortic surgery. Ann Thorac Surg. 2007;84:1592-9.

14. Jassar AS, Desai ND, Kobrin D, Pochettino A, Vallabhajosyula P, Milewski RK, et al. Outcomes of aortic root replacement after previous aortic root replacement: the "true" redo root. Ann Thorac Surg. 2015;99:1601-9.

15. El-Hamamsy I, Ibrahim M, Stevens LM, Witzke H, Clark L, Yacoub MH. Early and long-term results of reoperative total aortic root replacement with reimplantation of the coronary arteries. J Thorac Cardiovasc Surg. 2011;142:1473-7.

16. Garrido-Olivares L, Maganti M, Armstrong S, David TE. Clinical outcomes of aortic root replacement after previous aortic root replacement. J Thorac Cardiovasc Surg. 2013;146:611-5.

Key Words: reoperation, root replacement

\section{Discussion}

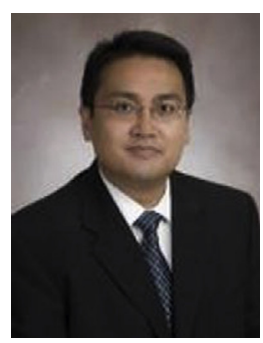

Dr A. Estrera (Houston, Tex). Dr Esaki and colleagues from the Emory group are to be congratulated on a report of an all-comers' approach to redo aortic root surgery. Despite the higher-risk profile of their consecutive patient cohort of 296 patients, the results were commendable, which is not unexpected from the technical expertise of Dr Chen and 
the group at Emory. I have 2 technical questions and 1 general question.

You reported reoperations in 20 patients of a prior homograft or a Ross. These are technically difficult procedures. Do you have any technical tips regarding these potentially difficult cases and how you approach these?

Dr Esaki (Atlanta, $\mathrm{Ga}$ ). Regarding the homograft, the calcification of the homografts allows us to know the exact location of the homograft. So if you dissect right along the calcified wall, the risk of injury to adjacent structures can be minimized. Sometimes calcification comes up to the ostium of the coronary arteries, so you must have an alternative technique in mind for coronary reimplantation such as Cabrol extensions.

Regarding the Ross procedure, because the autograft root is native tissue, usually there is no calcification. So it is usually straightforward to explant the autograft root. Sometimes there is adhesion to the pulmonary homograft, so you must prepare for potential injury to the pulmonary homograft. So even in the setting of a normal functioning pulmonic valve, we usually have a pulmonary homograft on standby just in case we injure the pulmonary homograft.

Dr Estrera. Another technical question. You had approximately $20 \%$ of patients with previous coronary bypass surgery. How did you deal with the patent left internal thoracic artery?

Dr Esaki. In such settings, we do not make an attempt to isolate the left internal thoracic artery. Our cardiac protection is based on a combination of continuous retrograde cardioplegia and intermittent antegrade cardioplegia down to the native coronaries and any patent vein grafts.

Dr Estrera. Emergency status was not associated with early mortality with univariate analysis but not with multivariate analysis. You had a large number of patients with prior acute type A dissection repair. In our experience, that has been a significant risk factor for mortality in those cases (patients who present with acute type A dissection and prior cardiac surgery). Did you look at that in a subgroup analysis specifically?

Dr Esaki. We had only 7 patients who presented with acute type A dissection and who underwent redo root replacement. The operative mortality of those patients was similar: $14 \%$. It was similar to the overall group. But we had 52 patients who had a history of type A repair and needed redo root replacement. The operative mortality of those patients was higher and reached $20 \%$. It is not significantly different from the overall group, but that group is a high-risk group. The pump and crossclamp times were longer, and two thirds of those patients required arch replacement.

Dr Estrera. What about endocarditis?

Dr Esaki. In our analysis, endocarditis is not a risk factor for operative mortality and long-term operative mortality.

Dr Estrera. The same could go for graft infection, because I thought that would have come out. But I guess it is the number; it is just not a large number of patients. Is that correct?

Dr Esaki. Yes.

Unidentified discussant. Do you have any hypotheses as to why a previous $C A B G$ would be more significant in terms of predicting mortality rather than a previous type A? I ask that because we previously published our data similar to this, but similarly, prior ascending aortic operations or prior aortic root operations did not predict a higher mortality. In our cases, a previous AVR had a higher mortality than a previous ascending, but I was hoping you have insight as to why $\mathrm{CABG}$ would have a higher mortality than a previous more complex aortic operation as Dr Estrera had suggested?

Dr Esaki. I think the one thing is cardiac protection. We do not make an attempt to isolate the left internal thoracic artery, so cardiac protection may not be good enough. Also, we have to dissect the vein graft and put the vein graft back up to the new graft, so sometimes we needed Cabrol extensions or other things. Probably those kinds of things negatively affect the outcomes. 


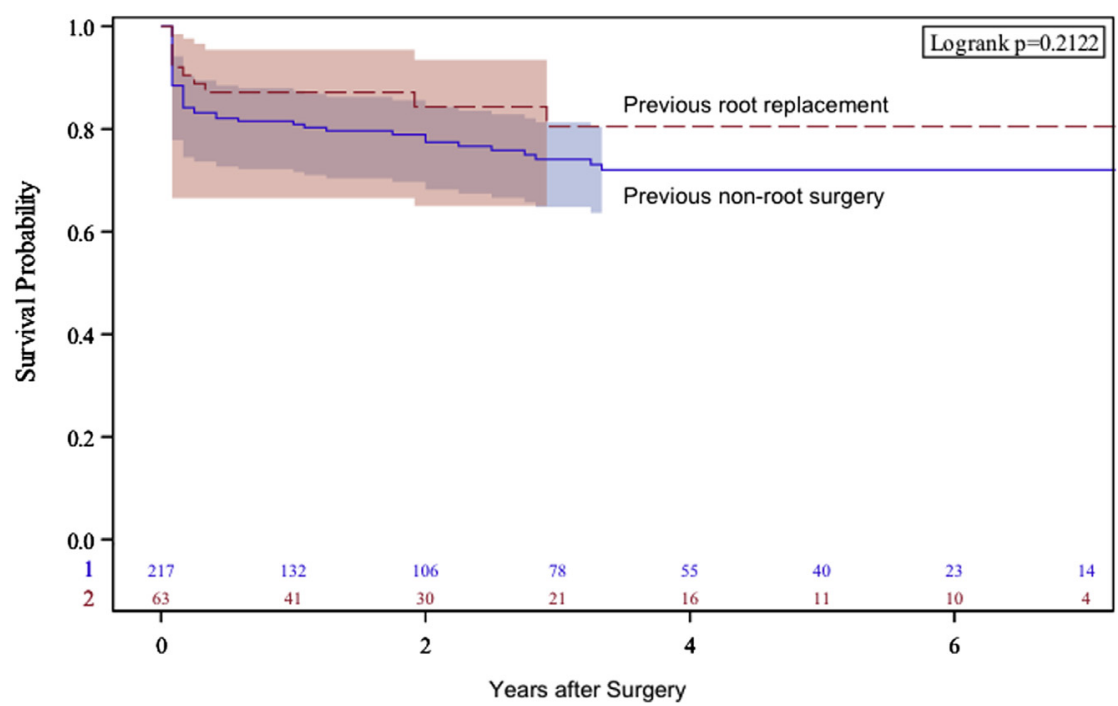

FIGURE E1. Long-term survival: previous root replacement versus previous nonroot surgery.

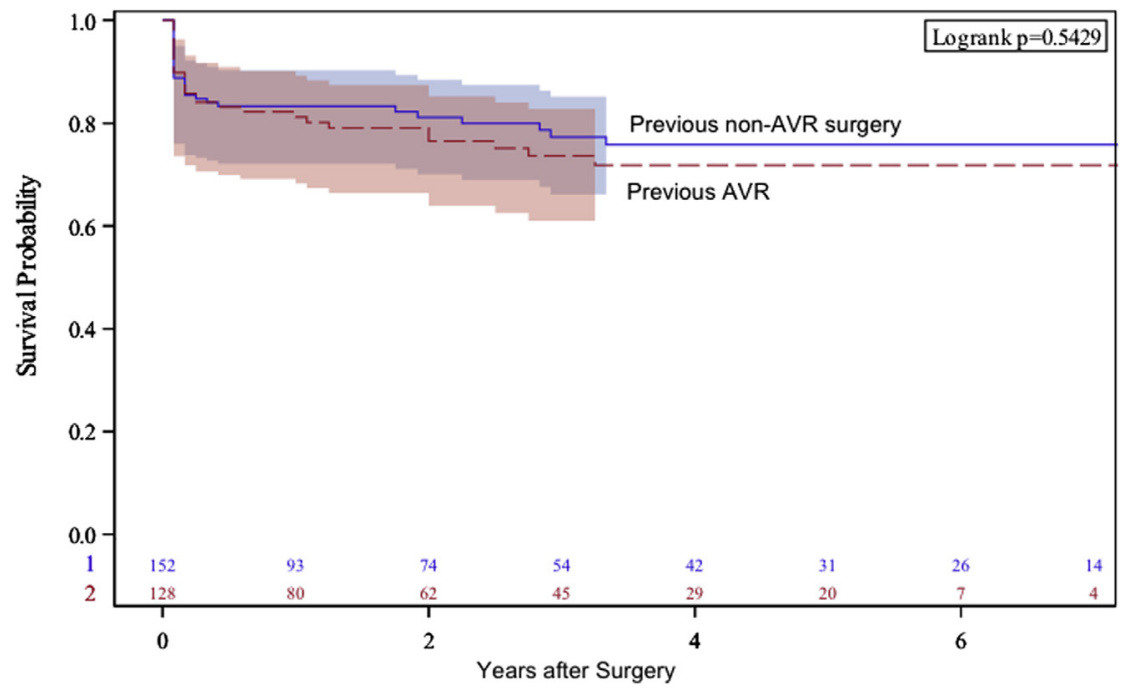

FIGURE E2. Long-term survival: previous AVR versus previous non-AVR surgery. AVR, Aortic valve replacement. 


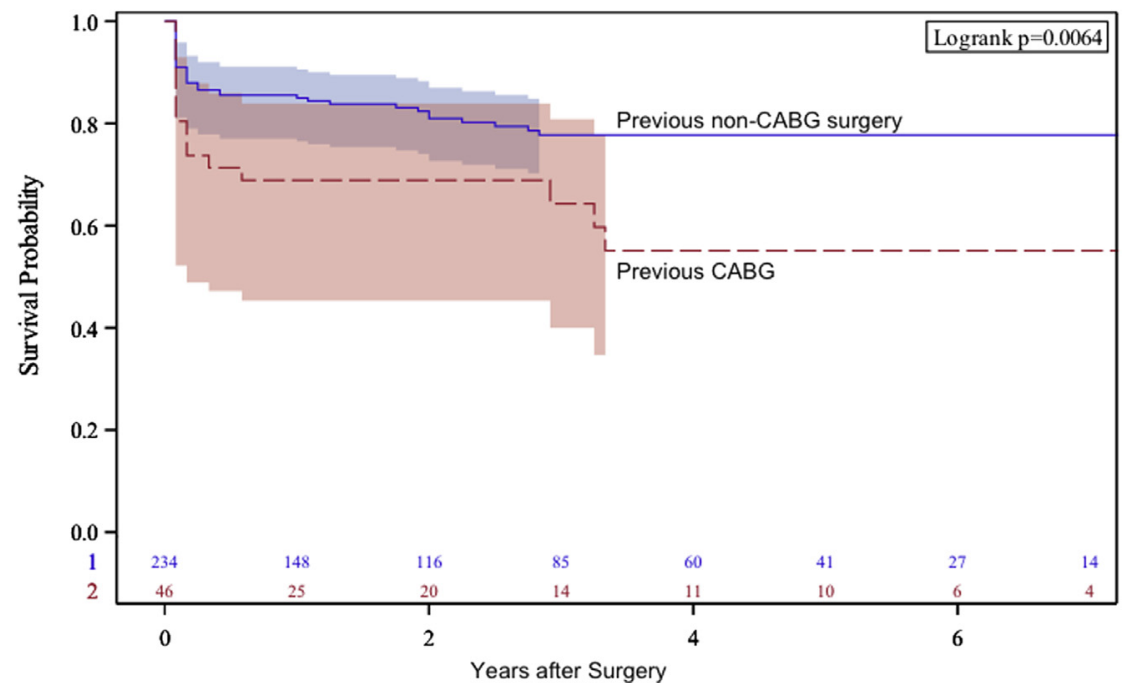

FIGURE E3. Long-term survival: previous $C A B G$ versus previous non-CABG surgery. $C A B G$, Coronary artery bypass grafting.

TABLE E1. Preoperative characteristics

\begin{tabular}{|c|c|c|c|c|c|c|c|}
\hline & $\begin{array}{c}\text { All } \\
(n=280)\end{array}$ & $\begin{array}{c}\text { Previous root } \\
\text { replacement }(n=63)\end{array}$ & $P$ value & $\begin{array}{c}\text { Previous } \\
\text { AVR }(\mathbf{n}=128) \\
\end{array}$ & $P$ value & $\begin{array}{c}\text { Previous } \\
\text { CABG }(n=46) \\
\end{array}$ & $P$ value \\
\hline Age, y, mean (SD) & $52.5(14.1)$ & $48.1(14.6)$ & .01 & $56.2(12.6)$ & $<.01$ & $59.5(13.2)$ & $<.01$ \\
\hline Male, n $(\%)$ & $216(77.1)$ & $55(87.3)$ & .03 & $87(68.0)$ & $<.01$ & $40(87.0)$ & .08 \\
\hline BMI, mean (SD) & $28.1(6.5)$ & $26.7(5.3)$ & .07 & $28.9(6.0)$ & .01 & $27.1(6.0)$ & .22 \\
\hline Cerebrovascular disease, $\mathrm{n}(\%)$ & $57(20.4)$ & 13 (20.6) & .95 & $33(25.8)$ & .04 & $7(15.2)$ & .34 \\
\hline Chronic lung disease, $\mathrm{n}(\%)$ & $55(19.6)$ & $11(17.5)$ & .62 & $27(21.1)$ & .57 & $16(34.8)$ & $<.01$ \\
\hline Diabetes mellitus, n (\%) & $46(16.4)$ & $11(17.5)$ & .8 & $23(18.0)$ & .52 & $8(17.4)$ & .85 \\
\hline Dyslipidemia, n (\%) & $167(59.6)$ & $36(57.1)$ & .65 & $83(64.8)$ & .10 & $37(80.4)$ & $<.01$ \\
\hline Hypertension, n (\%) & $222(79.3)$ & $52(82.5)$ & .47 & $98(76.6)$ & .30 & $42(91.3)$ & .03 \\
\hline Peripheral arterial disease, $\mathrm{n}(\%)$ & $19(6.8)$ & $4(6.3)$ & .99 & $4(3.1)$ & .03 & 9 (19.6) & $<.01$ \\
\hline Renal failure, n (\%) & $11(3.9)$ & $2(3.2)$ & .99 & $6(4.7)$ & .55 & $2(4.3)$ & .99 \\
\hline Dialysis-dependent renal failure, $\mathrm{n}(\%)$ & $5(1.8)$ & $1(1.6)$ & .99 & $2(1.6)$ & .99 & $1(2.2)$ & .99 \\
\hline Previous myocardial infarction, $\mathrm{n}(\%)$ & $32(11.4)$ & $8(12.7)$ & .72 & $8(6.3)$ & .01 & $18(39.1)$ & $<.01$ \\
\hline $\mathrm{CAD}, \mathrm{n}(\%)$ & $68(24.3)$ & $16(25.4)$ & .82 & $24(18.8)$ & .05 & 43 (93.5) & $<.01$ \\
\hline Ejection fraction $(\%)$, median (q1, q3) & $57.8(46.5,60.0)$ & $55.0(48.0,60.0)$ & .83 & $58.0(50.0,60.0)$ & .16 & $55.0(45.0,60.0)$ & .46 \\
\hline $\mathrm{EF}>50 \%, \mathrm{n}(\%)$ & $182(65.0)$ & $43(68.3)$ & .54 & $88(68.8)$ & .23 & $28(60.9)$ & .52 \\
\hline EF $31 \%-50 \%, n(\%)$ & $72(25.7)$ & $13(20.6)$ & .29 & $31(24.2)$ & .60 & $13(28.3)$ & .67 \\
\hline $\mathrm{EF} \leq 30 \%, \mathrm{n}(\%)$ & $26(9.3)$ & $7(11.1)$ & .57 & $9(7.0)$ & .23 & $5(10.9)$ & .78 \\
\hline Bicuspid aortic valve, n (\%) & $72(25.7)$ & $20(31.7)$ & .21 & $34(26.6)$ & .77 & $3(6.5)$ & $<.01$ \\
\hline Marfan syndrome, n (\%) & $14(5.0)$ & $5(7.9)$ & .32 & $3(2.3)$ & .06 & $2(4.3)$ & .99 \\
\hline Acute aortic dissection, $\mathrm{n}(\%)$ & $6(2.1)$ & $0(0.0)$ & .34 & $3(2.3)$ & .99 & $2(4.3)$ & .26 \\
\hline Endocarditis or graft infection, $(\%)$ & $50(17.9)$ & $18(28.6)$ & .01 & $31(24.2)$ & .01 & $8(17.4)$ & .93 \\
\hline Previous aortic surgery, n (\%) & $113(41.6)$ & $63(100.0)$ & - & $12(9.4)$ & $<.01$ & $19(41.3)$ & .89 \\
\hline Aortic root replacement, n (\%) & $63(22.5)$ & $63(100.0)$ & - & $\mathbf{0}(\mathbf{0 . 0})$ & $<.01$ & $13(28.3)$ & .31 \\
\hline Ascending aorta replacement, $\mathrm{n}(\%)$ & $85(30.4)$ & $41(65.1)$ & - & $9(7.0)$ & $<.01$ & $16(34.8)$ & .48 \\
\hline Aortic arch replacement, $\mathrm{n}(\%)$ & $15(5.4)$ & $7(11.1)$ & - & $3(2.3)$ & .04 & $4(8.7)$ & .28 \\
\hline $\begin{array}{l}\text { Type A dissection repair including root, } \\
\text { ascending and arch replacement, } \mathrm{n}(\%)\end{array}$ & $47(16.8)$ & $11(17.5)$ & - & $4(3.1)$ & $<.01$ & $8(17.4)$ & .90 \\
\hline $\begin{array}{l}\text { Previous valve surgery, excluding root } \\
\text { replacement, } \mathrm{n}(\%)\end{array}$ & $162(57.9)$ & $20(31.7)$ & $<.01$ & $128(100.0)$ & $<.01$ & $16(34.8)$ & $<.01$ \\
\hline AVR, n $(\%)$ & $128(45.7)$ & $\mathbf{0}(\mathbf{0 . 0})$ & $<.01$ & $128(100.0)$ & - & $13(28.3)$ & .01 \\
\hline Mitral valve replacement/repair, n (\%) & $26(9.3)$ & $1(1.6)$ & .02 & $13(10.2)$ & .65 & $1(2.2)$ & .09 \\
\hline Pulmonic valve replacement/repair, n (\%) & $22(7.9)$ & $19(30.2)$ & $<.01$ & $0(0.0)$ & $<.01$ & $2(4.3)$ & .99 \\
\hline Previous CABG, $\mathrm{n}(\%)$ & $46(16.4)$ & $13(20.6)$ & .31 & $13(10.2)$ & .01 & $46(100.0)$ & - \\
\hline Years from previous surgery, median $(\mathrm{q} 1, \mathrm{q} 3)$ & $9.3(3.7,15.4)$ & $7.9(3.0,12.7)$ & .05 & $9.1(4.6,16.1)$ & .99 & $6.0(2.3,9.8)$ & $<.01$ \\
\hline
\end{tabular}

Statistically significant results are shown in boldface. $A V R$, Aortic valve replacement; $C A B G$, coronary artery bypass grafting; $S D$, standard deviation; $B M I$, body mass index; $C A D$, coronary artery disease; $E F$, ejection fraction. 
TABLE E2. Operation data

\begin{tabular}{|c|c|c|c|c|c|c|c|}
\hline & $\begin{array}{c}\text { All } \\
(\mathbf{n}=\mathbf{2 8 0})\end{array}$ & $\begin{array}{c}\text { Previous root } \\
\text { replacement }(n=63)\end{array}$ & $\begin{array}{c}P \\
\text { value }\end{array}$ & $\begin{array}{c}\text { Previous AVR } \\
\quad(\mathbf{n}=\mathbf{1 2 8})\end{array}$ & $\begin{array}{c}P \\
\text { value }\end{array}$ & $\begin{array}{c}\text { Previous } \\
\text { CABG }(n=46)\end{array}$ & $\begin{array}{c}P \\
\text { value }\end{array}$ \\
\hline Emergency, n (\%) & $13(4.6)$ & $3(4.8)$ & .99 & $9(7.0)$ & .08 & $2(4.3)$ & .99 \\
\hline \multicolumn{8}{|l|}{ Root replacement } \\
\hline With mechanical valve, n (\%) & $62(22.1)$ & $14(22.2)$ & .99 & $29(22.7)$ & .85 & $6(13.0)$ & .10 \\
\hline With bioprosthetic valve, $\mathrm{n}(\%)$ & $123(43.9)$ & $26(41.3)$ & .63 & $49(38.3)$ & .08 & $26(56.5)$ & .06 \\
\hline With homograft, n (\%) & $43(15.4)$ & $15(23.8)$ & .03 & $27(21.1)$ & .01 & $7(15.2)$ & .98 \\
\hline With valve sparing, $\mathrm{n}(\%)$ & $26(9.3)$ & $6(9.5)$ & .94 & $\mathbf{0}(\mathbf{0 . 0})$ & $<.01$ & $5(10.9)$ & .78 \\
\hline With Ross procedure, $\mathrm{n}(\%)$ & $5(1.8)$ & $1(1.6)$ & .99 & $3(2.3)$ & .66 & $0(0.0)$ & .99 \\
\hline With prosthesis sparing, $\mathrm{n}(\%)$ & $21(7.5)$ & $1(1.6)$ & .05 & $20(15.6)$ & $<.01$ & $2(4.3)$ & .54 \\
\hline Mitral valve replacement or repair, n (\%) & $18(6.4)$ & $2(3.2)$ & .38 & $11(8.6)$ & .18 & $1(2.2)$ & .32 \\
\hline Pulmonic valve replacement, $\mathrm{n}(\%)$ & $25(8.9)$ & $13(20.6)$ & $<.01$ & $4(3.1)$ & $<.01$ & $\mathbf{0}(\mathbf{0 . 0})$ & .02 \\
\hline Tricuspid valve repair, n (\%) & $5(1.8)$ & $1(1.6)$ & .99 & $4(3.1)$ & .18 & $0(0.0)$ & .99 \\
\hline CABG, $n(\%)$ & $68(24.3)$ & $19(30.2)$ & .22 & $32(25.0)$ & .80 & $24(52.2)$ & $<.01$ \\
\hline Due to CAD, n (\%) & $28(10.0)$ & $3(4.8)$ & .12 & $14(10.9)$ & .63 & $18(39.1)$ & $<.01$ \\
\hline Due to adhesion, $\mathrm{n}(\%)$ & $7(2.5)$ & $3(4.8)$ & .19 & $3(2.3)$ & .99 & $1(2.2)$ & .99 \\
\hline Due to anatomy, n (\%) & $13(4.6)$ & $5(7.9)$ & .18 & $6(4.7)$ & .97 & $2(4.3)$ & .99 \\
\hline Due to infection, $\mathrm{n}(\%)$ & $4(1.4)$ & $1(1.6)$ & .99 & $3(2.3)$ & .33 & $1(2.2)$ & .51 \\
\hline Due to injury, $\mathrm{n}(\%)$ & $9(3.2)$ & $4(6.3)$ & .12 & $4(3.1)$ & .99 & $1(2.2)$ & .99 \\
\hline Due to new myocardial ischemia, $\mathrm{n}(\%)$ & $7(2.5)$ & $3(4.8)$ & .19 & $2(1.6)$ & .46 & $1(2.2)$ & .99 \\
\hline Cabrol extension, n (\%) & $15(5.4)$ & $5(7.9)$ & .34 & $10(7.8)$ & .09 & $1(2.2)$ & .48 \\
\hline Aortic arch replacement, $\mathrm{n}(\%)$ & $135(48.2)$ & $31(49.2)$ & .86 & $62(48.4)$ & .95 & $21(45.7)$ & .70 \\
\hline Hemiarch replacement, n (\%) & $106(37.9)$ & $25(39.7)$ & .73 & $53(41.4)$ & .26 & $18(39.1)$ & .85 \\
\hline Total arch replacement, $\mathrm{n}(\%)$ & $29(10.4)$ & $6(9.5)$ & .81 & $9(7.0)$ & .09 & $3(6.5)$ & .44 \\
\hline \multicolumn{8}{|l|}{ Arterial cannulation site, $\mathrm{n}(\%)$} \\
\hline Aorta, n (\%) & $106(37.9)$ & $26(41.3)$ & .53 & $50(39.1)$ & .70 & $13(28.3)$ & .14 \\
\hline Axillary artery, $\mathrm{n}(\%)$ & $158(56.4)$ & $30(47.6)$ & .11 & $75(58.6)$ & .50 & $32(69.6)$ & .05 \\
\hline Femoral artery, n (\%) & $16(5.7)$ & $7(11.1)$ & .06 & $3(2.3)$ & .03 & $1(2.2)$ & .48 \\
\hline CPB time (min), median (q1, q3) & $240.5(205.5,283.0)$ & $261.0(220.0,298.0)$ & .01 & $233.5(201.5,275.0)$ & .09 & $241.5(202.0,297.0)$ & .94 \\
\hline Crossclamp time $(\min )$, median $(\mathrm{q} 1, \mathrm{q} 3)$ & $198.0(171.5,225.0)$ & $211.0(188.0,249.0)$ & .01 & $192.0(172.5,219.0)$ & .14 & $186.0(166.0,215.0)$ & .07 \\
\hline Circulatory arrest, $\mathrm{n}(\%)$ & $144(51.4)$ & $35(55.6)$ & .46 & $64(50.0)$ & .66 & $26(56.5)$ & .45 \\
\hline Antegrade cerebral perfusion, n (\%) & $124(44.3)$ & $25(39.7)$ & .40 & $60(46.9)$ & .42 & $22(47.8)$ & .60 \\
\hline $\mathrm{ACP}$ and RCP, n (\%) & $2(0.7)$ & $1(1.6)$ & .40 & $0(0.0)$ & .50 & $0(0.0)$ & .99 \\
\hline Retrograde cerebral perfusion, $\mathrm{n}(\%)$ & $10(3.6)$ & $3(4.8)$ & .70 & $4(3.1)$ & .76 & $0(0.0)$ & .38 \\
\hline Deep hypothermic circulatory arrest, $\mathrm{n}(\%)$ & $8(2.9)$ & $6(9.5)$ & $<.01$ & $\mathbf{0}(\mathbf{0 . 0})$ & .01 & $4(8.7)$ & .03 \\
\hline Circulatory arrest time $(\min )$, median $(\mathrm{q} 1, \mathrm{q} 3)$ & $26.0(22.0,38.5)$ & $24.0(23.0,35.0)$ & .97 & $25.0(21.0,32.0)$ & .04 & $23.0(19.0,38.0)$ & .11 \\
\hline
\end{tabular}

Statistically significant results are shown in boldface. $A V R$, Aortic valve replacement; $C A B G$, coronary artery bypass grafting; $C A D$, coronary artery disease; $C P B$, cardiopulmonary bypass; $A C P$, antegrade cerebral perfusion; $R C P$, retrograde cerebral perfusion.

TABLE E3. Mortality and morbidities

\begin{tabular}{|c|c|c|c|c|c|c|c|}
\hline & All $(\mathbf{n}=\mathbf{2 8 0})$ & $\begin{array}{c}\text { Previous root } \\
\text { replacement }(n=63)\end{array}$ & $\begin{array}{c}P \\
\text { value } \\
\end{array}$ & $\begin{array}{c}\text { Previous } \\
\text { AVR }(\mathbf{n}=128) \\
\end{array}$ & $\begin{array}{c}P \\
\text { value }\end{array}$ & $\begin{array}{c}\text { Previous } \\
\text { CABG }(n=46)\end{array}$ & $\begin{array}{c}P \\
\text { value }\end{array}$ \\
\hline Reexploration for bleeding, $\mathrm{n}(\%)$ & $31(11.1)$ & $11(17.5)$ & .07 & $10(7.8)$ & .11 & $8(17.4)$ & .14 \\
\hline Prolonged ventilation (>24 h), n (\%) & $105(37.5)$ & $22(34.9)$ & .63 & $53(41.4)$ & .22 & $21(45.7)$ & .21 \\
\hline Intra-aortic balloon pump required, $\mathrm{n}(\%)$ & $60(21.4)$ & $19(30.2)$ & .06 & $24(18.8)$ & .32 & $14(30.4)$ & .10 \\
\hline New dialysis required, $\mathrm{n}(\%)$ & $14(5.0)$ & $2(3.2)$ & .74 & $8(6.3)$ & .38 & $6(13.0)$ & .02 \\
\hline Transient neurologic dysfunction, $\mathrm{n}(\%)$ & $12(4.3)$ & $2(3.2)$ & .99 & $5(3.9)$ & .77 & $5(10.9)$ & .03 \\
\hline Permanent neurologic dysfunction, $\mathrm{n}(\%)$ & $14(5.0)$ & $2(3.2)$ & .99 & $7(5.5)$ & .74 & $1(2.2)$ & .48 \\
\hline Pacemaker implantation, n (\%) & $9(3.2)$ & $1(1.6)$ & .69 & $6(4.7)$ & .31 & $0(0.0)$ & .36 \\
\hline Deep sternal infection, n (\%) & $3(1.1)$ & $0(0.0)$ & .99 & $2(1.6)$ & .59 & $0(0.0)$ & .99 \\
\hline ICU stay $(h)$, median $(q 1, q 3)$ & $67.5(40.5,134.3)$ & $66.0(40.5,134.8)$ & .62 & $85.0(43.5,149.2)$ & .04 & $91.4(40.2,160.7)$ & .62 \\
\hline Length of stay $(\mathrm{d})$, median $(\mathrm{q} 1, \mathrm{q} 3)$ & $7.0(5.0,11.0)$ & $8.0(6.0,12.0)$ & .45 & $8.0(6.0,11.5)$ & .03 & $7.5(4.0,12.0)$ & .42 \\
\hline Operative mortality, n (\%) & $40(14.3)$ & $6(9.5)$ & .22 & $18(14.1)$ & .92 & $12(26.1)$ & .01 \\
\hline
\end{tabular}

Statistically significant results are shown in boldface. $A V R$, Aortic valve replacement; $C A B G$, coronary artery bypass grafting; $I C U$, intensive care unit. 